\title{
Hacia la transformación educativa en ingeniería
}

\author{
Luis Alberto Tafur Jiménez ${ }^{1 *}$
}

*Autor correspondiente: luis.tafur@usbmed.edu.co

Facultad de Ingenierías, Universidad de San Buenaventura, Medellín, Colombia.

Uno de los grandes retos a nivel mundial es incentivar la creación de conocimiento e impulsar la innovación con el fin de generar estrategias y recursos que permitan a las personas tener acceso a una educación inclusiva y equitativa de calidad. En este reto, expertos en educación en el mundo manifiestan la existencia de un problema que afecta la calidad y pertinencia de la misma, es la brecha entre lo que se enseña y cómo se trasmite, respecto a las competencias que deben adquirir los profesionales para resolver los problemas de la sociedad. Las Instituciones de Educación Superior (IES), responsables del último ciclo de formación antes de que el profesional inicie su vida laboral, tienen la responsabilidad de entender los problemas actuales de la sociedad y articularlos a sus funciones sustantivas de docencia, investigación y proyección social. En el caso de la ingeniería, el reto incluye la búsqueda de soluciones a nivel tecnológico para responder a las necesidades de la creciente población mundial teniendo en cuenta cuatro temas transversales: la sostenibilidad, la salud, la vulnerabilidad y la calidad de vida.

Estos cuatro pilares son tenidos en cuenta por un grupo internacional de expertos en tecnología convocados por la National Science Foundation de Estados Unidos, quienes identifican catorce principales desafíos de la ingeniería en el siglo XXI. El reto en el país de las IES que cuentan con escuelas de ingeniería es identificar cuáles de estos desafíos son los más relevantes para el desarrollo a nivel nacional, teniendo en cuenta la dinámica empresarial y las metas gubernamentales en torno a los cuatro ejes transversales de sostenibilidad, salud, vulnerabilidad y calidad de vida. Por tanto, la proyección social o interacción de la universidad con la industria y el estado debe propiciar un dialogo permanente, en el cual la identificación de las principales problemáticas del sector productivo sea una prioridad para la academia.

Para ello, las IES manejan diversos mecanismos que van desde la inclusión en los currículos de las prácticas profesionales, la creación de unidades de negocio para la realización de proyectos de ingeniería o el establecimiento de consultorios tecnológicos para brindar asesorías a la comunidad. Más allá del mecanismo utilizado, lo importante es entender la finalidad de la proyección social enmarcada en un dialogo permanente con el sector productivo, que busca identificar los problemas de la sociedad relacionados con el desarrollo tecnológico. Es así como la práctica profesional de un estudiante puede retroalimentar el currículo proporcionando información sobre necesidades de formación en el campo, o la realización de proyectos de ingeniería puede dejar como producto planteamientos de nuevos problemas ingenieriles por resolver. Lo importante a partir de este punto es lograr sacar el mayor beneficio de esta información y articularla de manera eficiente con los procesos de investigación y docencia. Para dar un ejemplo, los problemas tecnológicos identificados en la ejecución de los proyectos de ingeniería deberían ser un insumo para la formulación de nuevos proyectos de investigación.

De las funciones sustantivas en una IES la investigación es tal vez la más importante, ya que de ella depende la generación de nuevo conocimiento, y a su vez, es la función que de alguna manera está cuantificando la capacidad de la institución para aplicar la ciencia en beneficio de la sociedad. En la medida en que la investigación tome como insumo la información obtenida mediante la proyección social, los productos o resultados de la misma tendrán un mayor impacto sobre la comunidad. Entre los mecanismos que las IES pueden implementar para tener una investigación que aporte a una educación de calidad están los trabajos de grado, la participación de estudiantes en semilleros de investigación, la gestión por proyectos, la inclusión de la empresa o el estado para validación de los productos de investigación y la cuantificación del impacto o retorno, ya sea económico, ambiental y/o social. La articulación de la investigación con otras funciones sustantivas debería darse mediante la creación de nuevos productos o servicios con valor agregado a nivel tecnológico, de manera que las IES puedan proyectarse en la sociedad por medio del acompañamiento a la empresa en el proceso de insertar en el mercado estos nuevos productos tecnológicos. En materia de docencia, la investigación suministra un insumo para el ejercicio en el aula, con el cual los profesores pueden enseñar de los resultados de sus proyectos de investigación. De esta manera, el proceso de enseñanza aprendizaje se enriquece, ya que es posible transmitir la generación de nuevo conocimiento de casos reales de resolución de problemas de la sociedad, producto de la participación en proyectos investigación o de- 
sarrollo ingenieril.

La calidad en la educación en materia de docencia depende en gran parte de la motivación de los docentes para articular las funciones sustantivas de investigación y proyección social a su ejercicio en el aula. Lo anterior indica que debe hacerse un esfuerzo para desincentivar el uso de metodologías de enseñanza tradicionales e incentivar la aplicación de metodologías alternativas que permitan la articulación entre funciones sustantivas. Para ello, es primordial tener presente la contribución de la proyección social, con la cual es posible identificar las necesidades de formación o competencias que deben adquirir los futuros profesionales. Es así como, la formación por competencias se vuelve un factor trascendental garante de una educación de calidad, lo cual exige necesariamente emplear otras metodologías de enseñanza y métodos de evaluación, que permitan valorar la adquisición de competencias de los estudiantes. Estas metodologías alternas no pueden ser diferentes a la dinámica en investigación y al ejercicio ingenieril que se vive día a día en el sector productivo, es decir, el aprendizaje debe basarse en proyectos y resolución de problemas. Entender el rol de cada función sustantiva, su contribución al proceso de enseñanza aprendizaje y la manera correcta de articulación entre ellas, es el camino hacia una transformación educativa en ingenierías, con el fin de crear conocimiento e innovación que ayude a conseguir la meta de una educación de calidad equitativa e inclusiva. 